\title{
Regulation of Gastroduodenal Motility: Acyl Ghrelin, Des-Acyl Ghrelin and Obestatin and Hypothalamic Peptides
}

\author{
Mineko Fujimiya $^{a}$ Koji Ataka ${ }^{a}$ Akihiro Asakawa $^{b}$ Chih-Yen Chen ${ }^{d}$ Ikuo Kato ${ }^{c}$ \\ Akio Inui $^{\text {b }}$ \\ ${ }^{a}$ Department of Anatomy, Sapporo Medical University School of Medicine, Sapporo, ${ }^{b}$ Department of Behavioral \\ Medicine, Kagoshima University Graduate School of Medical and Dental Sciences, Kagoshima, and ' Department of \\ Bioorganic Chemistry, Faculty of Pharmaceutical Sciences, Hokuriku University, Kanazawa, Japan; ${ }^{d}$ Faculty of \\ Medicine, National Yang-Ming University School of Medicine, and Division of Gastroenterology, Department of \\ Medicine, Taipei Veterans General Hospital, Taipei, Taiwan, ROC
}

\section{Key Words}

Gastroduodenal motility, regulation - Acyl ghrelin •

Des-acyl ghrelin • Obestatin $\cdot$ Hypothalamic peptides

\begin{abstract}
Real-time measurements for gut motility in conscious rats or mice combined with intracerebroventricular or intravenous injection of peptide agonists or antagonists allow us to understand the regulatory mechanism of gastrointestinal motility. Neuropeptide Y (NPY) in the arcuate nucleus in the hypothalamus stimulates the fasted motility in the duodenum, while urocortin in the paraventricular nucleus inhibits fed and fasted motility in the antrum and duodenum. Acyl ghrelin exerts stimulatory effects on the motility of the antrum and duodenum in both the fed and fasted state of animals. NPY Y 2 and Y4 receptors in the brain may mediate the action of acyl ghrelin, and vagal afferent pathways might be involved in this mechanism. Des-acyl ghrelin exerts inhibitory effects on the motility of the antrum but not on the motility of the duodenum in the fasted state of animals. CRF type 2 receptor in the brain may mediate the action of des-acyl ghrelin, and vagal afferent pathways might not be involved in this mechanism. Obestatin exerts inhibitory effects on the
\end{abstract}

motility of the antrum and duodenum in the fed state but not in the fasted state of animals. CRF type 1 and type 2 receptors in the brain may mediate the action of obestatin, and vagal afferent pathways might be partially involved in this mechanism.

Copyright $\odot 2012$ S. Karger AG, Basel

\section{Experimental Design for Studying Gastrointestinal Motility and Brain-Gut Axis}

Although the regulation of hypothalamic peptides on feeding behavior or energy expenditure has been well established, the regulation on the gastrointestinal (GI) motility has not been fully understood. The detailed studies on the brain-gut axis are somewhat hampered by the methodological difficulties in directly measuring the GI motility in conscious animals with intracerebroventricular (ICV) injection of peptide agonists or antagonists.

We developed a freely moving conscious animal model to measure the GI motility in rats [1] and mice [2], combined with intravenous (IV) or ICV injection. This model permits the real-time measurements of GI motility in

\section{KARGER}

Fax +4161306 1234 E-Mail karger@karger.ch www.karger.com (c) 2012 S. Karger AG, Basel 0012-2823/12/0852-0090\$38.00/0

Accessible online at: www.karger.com/dig
Mineko Fujimiya

Department of Anatomy

Sapporo Medical University School of Medicine

Sapporo 060-8556 (Japan)

Tel. +81 11611 2111, E-Mail fujimiya@ sapmed.ac.jp 
animals in the physiological fed and fasted states under stimulation of the brain or peripheral administration of peptide agonists or antagonists. In the fasted state, the cyclic change of pressure waves were detected in both antrum and duodenum, including the quiescence period during which relatively low amplitude contractions occur (phase I-like contractions), followed by a grouping of strong contractions (phase III-like contractions). After food intake, such a fasted motor pattern was disrupted and replaced by a fed motor pattern, which consisted of irregular contractions of high frequency. By using this method the effects of brain-gut peptides on the GI motility can be examined.

\section{Neuropeptide $Y$ and Urocortin in the Hypothalamus Regulate the Gastroduodenal Motility}

Neuropeptide Y (NPY) is a potent feeding-stimulatory peptide that expresses in the arcuate nucleus of the hypothalamus and projects predominantly to the paraventricular nucleus. Because few previous studies have examined the effects of centrally administered NPY-related peptide on GI motility, we investigated the role of NPY in the control of GI motility using a variety of NPY analogs [1]. ICV injection of Y2 and Y4 receptor agonists induced the phase III-like contractions in the duodenum when given in the fed state of rats; however, Y1 and Y5 receptor agonists had no effects on the motility despite their potent feeding-stimulatory effects [1]. More interestingly, immunoneutralization of NPY by ICV injection of NPY antibody completely blocked the phase III-like contractions in the duodenum [1]. This finding suggests that the fasted motor activity in the upper GI tracts is regulated by brain NPY neurons but not regulated by peripheral mechanism.

CRF and endogenous CRF receptor ligand urocortin are feeding-inhibitory peptides localized at the paraventricular nucleus in the hypothalamus. Urocortin binds both CRF type 1 and 2 receptors but shows a higher affinity for CRF type 2 receptor than type 1 receptor. CRF type 2 receptors are related to the stress-induced alterations of GI functions. ICV or IV injection of urocortin disrupted fasted motor activity in both antrum and duodenum, which were replaced by fed-like motor patterns [3]. When urocortin was given ICV in the fed state, the $\%$ motor index (\%MI) was decreased in the antrum and increased in the duodenum [3]. Increase the \%MI in the duodenum was non-propagated and therefore urocortin suppressed the transit of intestinal contents [3].

Regulation of Gastroduodenal Motility

\section{Colocalization of Acyl Ghrelin, Des-Acyl Ghrelin and Obestatin in Endocrine Cells in the Stomach}

Acyl ghrelin was first isolated from rat and human stomach [4], and the localization of acyl ghrelin in the stomach was studied in various animals by using the specific antibody for acyl ghrelin $[4,5]$; however, the localization of des-acyl ghrelin in the stomach has scarcely been examined. Our group developed antibodies specific for acyl ghrelin (anti-rat octanoyl ghrelin (1-15)-cys-KLH serum) and for des-acyl ghrelin (anti-rat des-octanoyl ghrelin (1-15)-cis-KLH serum) and successfully detected the different localization of acyl ghrelin and des-acyl ghrelin in the rat stomach [6].

Both acyl ghrelin- and des-acyl ghrelin-immunoreactive cells were distributed in the oxyntic and antral mucosa of the rat stomach, with higher density in the antral mucosa than oxyntic mucosa. Immunofluorescence double staining showed that acyl ghrelin- and des-acyl ghrelin-positive reactions overlapped in closed-type round cells, whereas des-acyl ghrelin-positive reaction was found in open-type cells in which acyl ghrelin was negative (fig. 1a). Acyl ghrelin/des-acyl ghrelin-positive closed-type cells contain obestatin (fig. 1b), on the other hand, des-acyl ghrelin-positive open-type cells contain somatostatin [6].

It is possible that open-type cells may react to luminal stimuli more than closed-type cells. Therefore, we investigated the effects of different intragastric $\mathrm{pH}$ levels on the release of acyl ghrelin and that of des-acyl ghrelin from the ex vivo perfused rat stomach [6]. The results showed that the release of acyl ghrelin was not affected by intragastric $\mathrm{pH}$, whereas the release of des-acyl ghrelin was increased at intragastric $\mathrm{pH} 2$ compared to that at intragastric $\mathrm{pH} 4$ [6]. Therefore, the release of des-acyl ghrelin is stimulated after meals by lowering the intragastric $\mathrm{pH}$. The release of acyl ghrelin, on the other hand, is stimulated before meals and the release is regulated by plasma levels of glucose and insulin [7].

\section{Regulation of Acyl Ghrelin on the Gastroduodenal Motility}

We examined the effects of acyl ghrelin on the gastroduodenal motility and involvement of hypothalamic peptides mediating this action. Acyl ghrelin stimulated the $\% \mathrm{MI}$ in the antrum and induced the fasted motor activity in the duodenum when given in the fed state of animals [8]. Acyl ghrelin increased the frequency of phase 

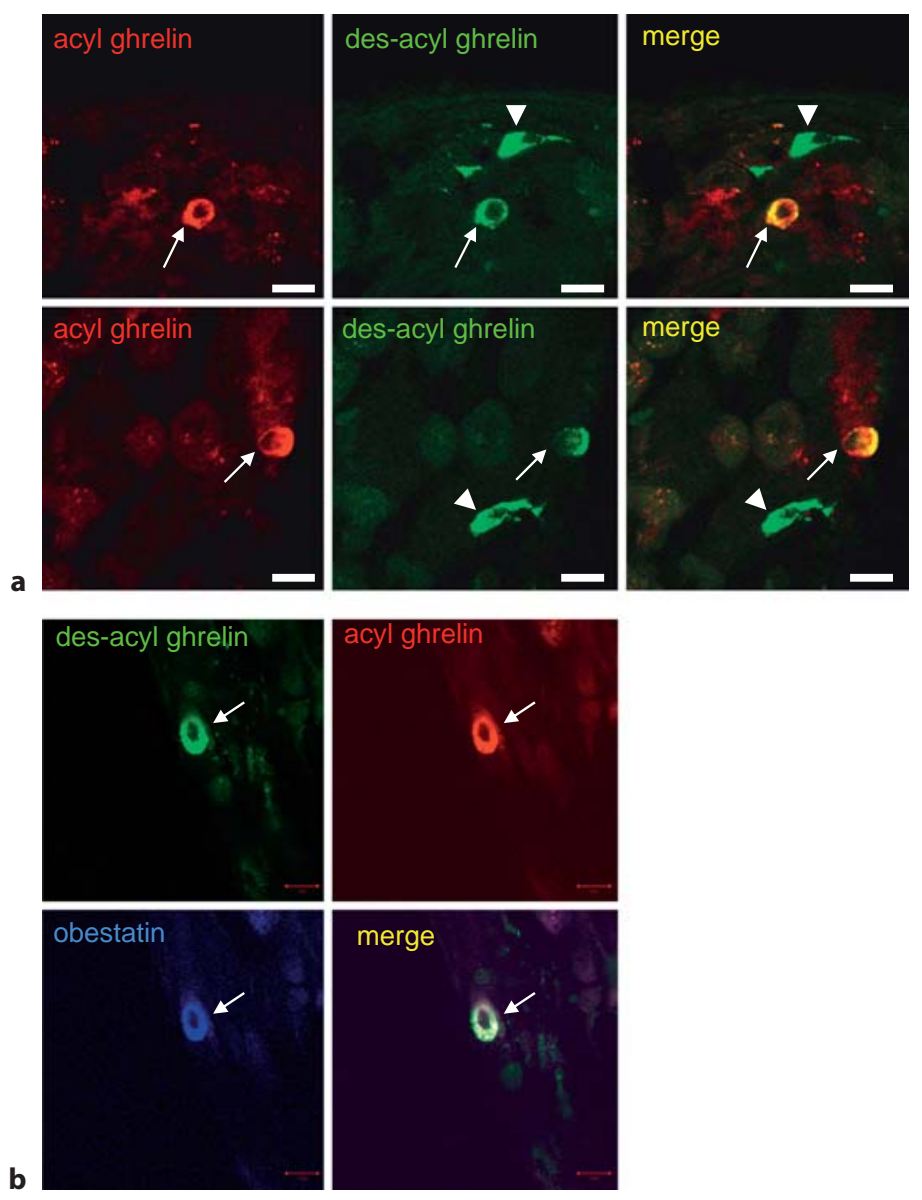

Fig. 1. Localization of acyl ghrelin, des-acyl ghrelin and obestatin in the rat stomach. a Immunofluorescence double staining for acyl ghrelin- (red) and des-acyl ghrelin-positive (green) reaction in the antral mucosa of rat stomach. Acyl ghrelin-positive reaction and des-acyl ghrelin-positive reaction are colocalized in closed-type cells (arrows), whereas des-acyl ghrelin-positive reaction is localized in open-type cells (arrowheads). b Immunofluorescence triple staining for des-acyl ghrelin (green), acyl ghrelin (red) and obestatin (blue) in the antral mucosa of rat stomach. Three peptides are colocalized in the closed-type cells (arrows). Bars $=10 \mu \mathrm{m}$ [from 6].

III-like contractions in both antrum and duodenum when given in the fasted state of animals [8]. The effects of IV injection of acyl ghrelin on gastroduodenal motility were blocked by IV injection of GHS-R antagonist [8]. Immunoneutralization of NPY in the brain blocked the stimulatory effects of acyl ghrelin on the gastroduodenal motility [8]. These results indicate that acyl ghrelin released from the stomach may act on the ghrelin receptor on vagal afferent nerve terminals and NPY neurons in the brain may mediate the action of acyl ghrelin on the gas-

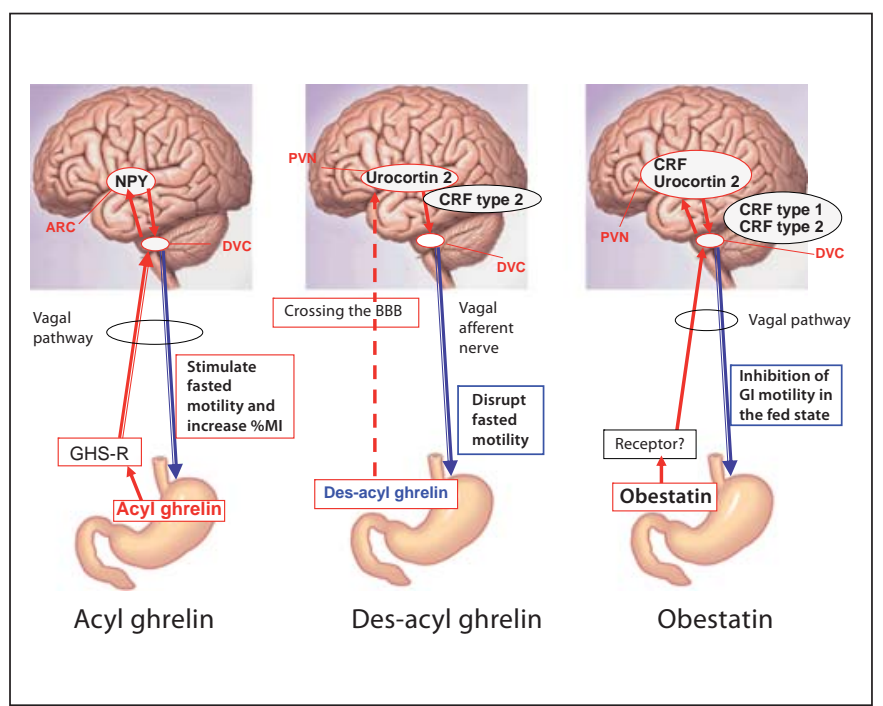

Fig. 2. Different pathways of acyl ghrelin, des-acyl ghrelin and obestatin. Acyl ghrelin released from the endocrine cells in the stomach may act on the ghrelin receptor on vagal afferent nerve terminals, and NPY neurons in the arcuate nucleus may mediate the action of acyl ghrelin to stimulate gastroduodenal motility. Des-acyl ghrelin released from endocrine cells in the stomach may activate urocortin-2 neurons in the paraventricular nucleus by crossing the $\mathrm{BBB}$, and exert inhibitory effects on the antral motility via CRF type 2 receptor in the brain. Obestatin may act on the obestatin receptor on vagal afferent nerve terminals, and CRF and urocortin-2 neurons in the paraventricular nucleus may mediate the action of obestatin to inhibit the gastroduodenal motility via CRF type 1 and type 2 receptors in the brain.

troduodenal motility. Taken together, in normal animals, acyl ghrelin may stimulate gastroduodenal motility by activating the GHS-R on vagal afferent nerve terminals and affect NPY neurons in the hypothalamus, Y2 and/or $\mathrm{Y} 4$ receptors in the brain may mediate the action of acyl ghrelin (fig. 2; table 1).

\section{Regulation of Des-Acyl Ghrelin on the Gastroduodenal Motility}

Des-acyl ghrelin disrupted fasted motility in the antrum but not in the duodenum; however, des-acyl ghrelin did not alter fed motor activity in both the antrum and duodenum [9]. Capsaicin treatment did not alter the disruptive effect of IV injection of des-acyl ghrelin on fasted motility in the antrum [9]. These results suggest that peripherally administered des-acyl ghrelin may cross the blood-brain barrier (BBB) and act directly on 
Table 1. Comparison of the effects of acyl ghrelin, des-acyl ghrelin and obestatin on the gastroduodenal motility

\begin{tabular}{|c|c|c|c|c|c|c|}
\hline & \multicolumn{2}{|l|}{ Acyl ghrelin } & \multicolumn{2}{|c|}{ Des-acyl ghrelin } & \multicolumn{2}{|l|}{ Obestatin } \\
\hline & fasted motility & fed motility & fasted motility & fed motility & fasted motility & fed motility \\
\hline Stomach & $\uparrow$ & $\uparrow$ & $\downarrow$ & - & - & $\downarrow$ \\
\hline Duodenum & $\uparrow$ & $\uparrow$ & - & - & - & $\downarrow$ \\
\hline Hypothalamic neuron & \multicolumn{2}{|l|}{ NPY } & \multicolumn{2}{|l|}{ Urocortin-2 } & \multicolumn{2}{|c|}{ CRF, urocortin-2 } \\
\hline Brain receptor & \multicolumn{2}{|l|}{$\mathrm{Y} 2, \mathrm{Y} 4$} & \multicolumn{2}{|l|}{ CRF type 2} & \multicolumn{2}{|c|}{ CRF type 1 , type 2} \\
\hline Vagal afferent pathway & \multicolumn{2}{|l|}{+} & \multicolumn{2}{|l|}{-} & \multicolumn{2}{|l|}{+} \\
\hline
\end{tabular}

the brain receptor and disrupt the fasted motility in the antrum.

The centrally administered CRF type 2 receptor antagonist, but not the CRF type 1 receptor antagonist, blocked the effects of centrally and peripherally administered des-acyl ghrelin on gastric motility [9]. The density of c-Fos-positive cells in the PVN was significantly increased by intraperitoneal injection of des-acyl ghrelin compared to vehicle-injected controls [9]. These data suggest that peripherally administered des-acyl ghrelin may activate neurons in the PVN by crossing the $\mathrm{BBB}$, and exert inhibitory effects on the antral motility via CRF type 2 receptor in the brain (fig. 2; table 1).

\section{Regulation of Obestatin on the Gastroduodenal Motility}

Most of the previous studies have shown the negative effects of obestatin on the GI motility; in those studies, however, only the gastric emptying or MMC cycle time has been used as indices for motor activity. We obtained the positive effects of obestatin on the gastroduodenal motility by analyzing the motor activity in fed and fasted states, and measuring the time taken to the initiation of phase III-like contractions in the antrum and duodenum of conscious rats [10].

Obestatin decreased the $\% \mathrm{MI}$ of fed motility in the antrum and prolonged the time before the return of fasted motility in the duodenum [10]. IV injection of obestatin induced a significant increase in the number of c-Fos-positive cells in the PVN compared to saline-injected controls [10]. Immunofluorescence overlap staining showed that the PVN neurons activated by IV injection of obestatin contain CRF or urocortin-2 [10]. The inhibitory action of IV injection of obestatin on the mo- tor activities in the antrum and duodenum were blocked by ICV injection of CRF type 1 and type 2 receptor antagonists, suggesting that both types of CRF receptors in the brain may mediate the action of peripherally injected obestatin on gastroduodenal motility [10]. Combined together, obestatin inhibits gastroduodenal motility in the fed state but not in the fasted state of conscious rats. In the brain, CRF- and urocortin-2-containing neurons might be activated by IV injection of obestatin, and at the level, CRF type 1 and type 2 receptors might be involved in the inhibitory action of obestatin on antral and duodenal motility. Vagal afferent pathways might be involved partially, but not entirely, in these actions of obestatin (fig. 2; table 1).

\section{Conclusions}

Acyl ghrelin, des-acyl ghrelin and obestatin are included in the endocrine cells in the stomach and regulate the upper GI motility by activating hypothalamic peptides [11, 12]. Since hypothalamic peptides are strongly affected by stress or anxiety, such brain-gut interaction seems to be important to understand the pathogenesis of functional disorder in the GI tracts.

\section{Disclosure Statement}

The authors declare that no financial or other conflict of interest exists in relation to the content of the article. 


\section{References}

1 Fujimiya M, Itoh E, Kihara N, Yamamoto I, Fujimura M, Inui A: Neuropeptide Y induces fasted pattern of duodenal motility via Y2 receptors in conscious fed rats. Am J Physiol Gastrointest Liver Physiol 2000;278:G32G38.

\2 Tanaka R, Inui A, Asakawa A, Atsuchi K, Ataka K, Fujimiya M: New method of manometric measurement of gastroduodenal motility in conscious mice: effects of ghrelin and Y2 depletion. Am J Physiol Gastrointest Liver Physiol 2009;297:G1028-G1034.

$\checkmark 3$ Kihara N, Fujimura M, Yamamoto I, Itoh E, Inui A, Fujimiya M: Effect of central and peripheral urocortin on fed and fasted gastroduodenal motor activity in conscious rats. Am J Physiol Gastrointest Liver Physiol 2001; 280:G406-G419.
Kojima M, Hosoda H, Date Y, Nakazato M, Matsuo H, Kangawa K: Ghrelin is a growthhormone-releasing acylated peptide from stomach. Nature 1999;402:656-660.

5 Sakata I, Mori T, Kaiya H, Yamazaki M, Kangawa K, Inoue K, Sakai T: Localization of ghrelin-producing cells in the stomach of the rainbow trout (Oncorhynchus mykiss). Zoo$\log$ Sci 2004;21:757-762

6 Mizutani M, Atsuchi K, Asakawa A, Matsuda N, Fujimura M, Inui A, Kato I, Fujimiya M: Localization of acyl ghrelin- and des-acyl ghrelin-immunoreactive cells in the rat stomach and their responses to intragastric pH. Am J Physiol Gastrointest Liver Physiol 2009;297:G974-G980.

7 Chen CY, Asakawa A, Fujimiya M, Lee SD, Inui A: Ghrelin gene products and the regulation of food intake and gut motility. Phamacol Rev 2009;61:430-481.

${ }_{8}$ Fujino K, Inui A, Asakawa A, Kihara N, Fujimura M, Fujimiya M: Ghrelin-induced fasted motor activity of the gastrointestinal tract in conscious fed rats. J Physiol 2003; 550:227-240.
9 Chen CY, Inui A, Asakawa A, Fujino K, Kato K, Chen CC, Ueno N, Fujimiya M: Des-acyl ghrelin acts by CRF type 2 receptors to disrupt fasted stomach motility in conscious rats. Gastroenterology 2005;129:8-25.

10 Ataka K, Inui A, Asakawa A, Kato I, Fujimiya $\mathrm{M}$ : Obestatin inhibits motor activity in the antrum and duodenum in the fed state of conscious rats. Am J Physiol Gastrointest Liver Physiol 2008;294:G1210-G1218.

11 Fujimiya M, Asakawa A, Ataka A, Kato I, Inui A: Different effects of ghrelin, des-acyl ghrelin and obestatin on gastroduodenal motility in conscious rats. World J Gastroenterol 2008; 14:6318-6326.

12 Fujimiya M, Asakawa A, Ataka K, Chen CY, Kato I, Inui A: Ghrelin, des-acyl ghrelin, and obestatin: regulatory roles on the gastrointestinal motility. Int J Pept 2010;2010. pii: 305192. 